\title{
Sürekli Uzayda Tesis Yeri Seçimi İçin Matematiksel Model: p-Medyan Problemi
}

\author{
Melike Kübra Ekiz Bozdemir ${ }^{1 *}$, Selen Avc1 ${ }^{2}$, Celal Özkale ${ }^{3}$ \\ 1* Kocaeli Üniversitesi, Mühendislik Fakültesi, Endüstri Mühendisliği Bölümü, Kocaeli, Türkiye, (ORCID: 0000-0003-3340-0484), melike.ekiz@kocaeli.edu.tr \\ ${ }^{2}$ Kocaeli Üniversitesi, Mühendislik Fakültesi, Endüstri Mühendisliği Bölümü, Kocaeli, Türkiye, (ORCID: 0000-0001-7433-5696), selen.avci@kocaeli.edu.tr \\ ${ }^{3}$ Kocaeli Üniversitesi, Mühendislik Fakültesi, Endüstri Mühendisliği Bölümü, Kocaeli, Türkiye, (ORCID: 0000-0003-0115-0505), cozkale@,kocaeli.edu.tr
}

(1st International Conference on Applied Engineering and Natural Sciences ICAENS 2021, November 1-3, 2021)

(DOI: 10.31590 /ejosat.1001560)

ATIF/REFERENCE: Ekiz Bozdemir, M. K., Avc1, S., \& Özkale, C. (2021). Sürekli Uzayda Tesis Yeri Seçimi İçin Matematiksel Model: p-Medyan Problemi. Avrupa Bilim ve Teknoloji Dergisi, (28), 386-390.

$\ddot{\mathbf{O} z}$

Günümüzün rekabetçi ortamında organizasyonların önem vermesi gereken stratejik kararlardan biri de tesis yer seçimi problemidir. Tesis yer seçimi problemlerinden biri olan $p$-medyan problemi, $n$ adet düğüm noktasını kullanarak $p$ tane tesisin konumunu, düğüm noktaları ile tesisler arasındaki taşımalardan kaynaklanan maliyetin minimize edilmesini sağlayarak elde etmeyi amaçlamaktadır. Bir diğer ifade ile $p$-medyan problemi $p$ adet tesisin hangi aday bölgelere kurulacağının ve hangi müşterilerin hangi tesise atanacağının belirlenmesi problemidir. Problemde dügüm noktalarının talepleri sabit, hizmete sunulan tesislerin sayısı ve konumlarının bilindiği varsayıldığından problem kesikli uzayda tesis yer seçimi problemi içerisinde sınıflandırılmaktadır. Bu çalışmada ise $p$-medyan probleminde yer alan alternatif tesislerin konumlarının bilinmediği varsayılmış ve Karar Verici (KV) tarafından belirlenmiş olan $p$ adet tesisin konumu matematiksel model yardımı ile elde edilmiştir. Sürekli uzayda tesis yer seçimi problemi olarak adlandırılan bu problem için Karesel Öklid uzaklığı kullanılarak doğrusal olmayan matematiksel model ele alınmıştır. Matematiksel modelin çözümü için GAMS 22.5 programı BARON çözücüsünden yararlanılmıştır.

Anahtar Kelimeler: Tesis Yeri Seçimi, Sürekli Uzayda Tesis Yeri Seçimi, P-Medyan Problemi, Matematiksel Model, Doğrusal Olmayan Programlama.

\section{Mathematical Model for Facility Location Problems in Continuous Space: $p$-Median Problem}

\begin{abstract}
In our world where competition is increasing day by day, one of the strategic decisions that organizations should pay attention to is facility location problem. The $p$-median problem, which is one of the facility location problems, aims to obtain the location of $p$ facilities by using $n$ nodes to aim minimizing the cost of transportation between the nodes and the facilities. In other words, the $p$-median problem determine in which $p$ facilities will be constructed and which customers will be assigned to which facility. The problem is classified as a facility location problem in discrete space, since it is assumed that the demands of the nodes are fixed, and the number and locations of the facilities are known. In this study, it is assumed that the locations of the alternative facilities are not known, and the locations of the $p$ facilities determined by the Decision Maker (DM) are obtained with a mathematical model. For this problem, which is called the facility location problem in continuous space, a nonlinear mathematical model is considered by using Euclidean Squared distance. The GAMS 22.5 program and BARON solver were used to solve the nonlinear mathematical model.
\end{abstract}

Keywords: Facility Location, Facility Location in Continuous Space, P-Median Problem, Mathematical Model, Nonlinear Mathematical Programming.

\footnotetext{
* Sorumlu Yazar: melike.ekiz@,kocaeli.edu.tr
} 


\section{Giriş}

Günümüzde firmalar arası rekabetin artması nedeniyle işletmelerin ayakta kalabilmesi ve büyüyebilmesi için maliyetlerini azaltmaları bir gerekliliktir. Firmaların en büyük maliyet kalemlerinden birisi lojistik maliyetleridir. Lojistik maliyetleri içerisinde; depolama, taşıma, geç teslimat, servis, stok bulundurma vb. maliyetler yer almaktadır. $\mathrm{Bu}$ maliyetlerin birçoğu tesis yeri seçimi ile doğrudan veya dolaylı olarak ilgilidir. Gerçek hayatta karşımıza çıkan tesis yeri seçimi problemlerinde dikkate alınması gereken birçok unsur bulunmaktadır. Bu unsurlar arasında; hammadde kaynaklarının, işgücünün, ulaştırma olanaklarının, enerji kaynaklarının, yan sanayinin şimdiki ve gelecekteki durumu ile talep ve dağıtım olanakları açısından pazarın elverişliliği sayılabilir (Karaoğlan, 2019).

Tesis yeri seçimi, $n$ adet tesisin $m$ adet ( $n<m$ olmak üzere) konuma taşıma maliyetlerinin minimize edilecek şekilde atanması problemi olarak tanımlanabilir. Tesis yeri seçim problemi, tesis yerinin kesikli veya sürekli uzayda olma durumuna göre sınıflandırılmaktadır. Sürekli uzayda tesis yeri seçimi probleminde, açılacak olan tesisler ve talepleri karşılanacak müşteriler düzlemde herhangi bir veya birden fazla noktaya yerleştirilir. Kesikli uzayda tesis yeri seçim probleminde ise tesislerin ve müşterilerin belirli düğüm noktalarına yerleştirilmesi söz konusudur. Bir diğer ifade ile sürekli uzayda tesis yeri seçim probleminde alternatif tesislerin konumları belirsiz iken kesikli uzayda tesis yeri seçim probleminde alternatifler ve konumları Karar Verici (KV), uzmanlar vb. tarafından belirlenmiştir. Kesikli uzayda tesis yeri seçim problemine örnek olarak $p$-medyan, $p$ merkez, istenmeyen tesis yeri seçimi, küme kapsama, ana dağıtım üssü seçim problemi, maksimum kapsama ve sabit maliyetli tesis yer seçimi verilebilir (Bast1, 2012).

Çalışmamızda kesikli tesis yeri seçim problemlerinden biri olan $p$-medyan problemi ele alınmıştır. $p$-medyan problemi, açılması istenen $p$ tane tesisin $n$ tane müşteri (talep) noktasına olan uzaklıklarını en küçükleyecek şekilde açılması ve açılan bu tesislere müşterilerin atanmasını sağlayan doğrusal modele sahip bir problemdir. $\mathrm{Bu}$ problemde, tesis ve müşterilerin konumları belirlidir. Çalışmada ele alınan problemde ise tesis konumlarının belirsiz olduğu varsayılarak geliştirilen doğrusal olmayan matematiksel model ile alternatif tesis yerlerinin konumları belirlenmiş ve amaç fonksiyonunu en küçükleyecek $p$ adet tesis açılmıştır. Son olarak müşteriler, talepleri karşılanacak şekilde açılmış olan tesislere atanmıştır. Geliştirilen doğrusal olmayan $p$ medyan probleminin amaç fonksiyonu, müşteriler ile tesisler arasındaki mesafeyi minimize etmeyi amaçlamaktadır. Müşteriler ile tesisler arasındaki mesafe karesel öklid uzaklığı ile incelenmiştir.

Çalışmanın ikinci bölümünde $p$-medyan problemine, üçüncü bölümünde ise doğrusal olmayan programlamaya sahip $p$-medyan problemine yer verilmiştir. Bölüm 4'te literatürden alınan veri seti, çalışma kapsamında geliştirilmiş olan matematiksel model doğrultusunda yeniden formüle edilerek çözüme ulaştırılmıştır. Çözüm için GAMS 22.5 paket programından ve BARON çözücüsünden yararlanılmıştır. Bölüm 5 'te ise GAMS çıktılarına ve sonuçlara yer verilmiştir.

\section{Metot}

\subsection{P-Medyan Problemi}

Tesis yeri seçim problemi, öncelikle büyük bir yatırım gerektirmesinden dolayı KV için önemli bir problemdir. Ayrıca problemde göz önüne alınması gereken birçok etken bulunmaktadır. Örneğin; tesisin kurulması için seçilen yerin müşterilere, tedarikçilere, depolara, pazara vb. olan uzaklıkları, gelecekteki işgücü durumu, yeryüzü şekilleri gibi etkenler sıralanabilir. Tesis yeri seçim problemi içerisinde yer alan kesikli uzayda tesis yeri seçim problemi genel olarak tesislerin belirlenen noktalara veya harita üzerinde istenilen noktaya yerleştirilmesi ve müşterilerin bu tesislere atanması problemi olarak tanımlanabilir. Kesikli uzayda tesis yeri problemlerinden biri olan $p$-medyan problemi ise $n$ adet müşterinin taleplerini karşılamak koşuluyla genellikle amaç fonksiyonunu en küçükleyecek şekilde $p$ adet tesisin açılması ve açılan bu tesislere müşterilerin atanması problemidir (Hillsman, 1984). Burada amaç fonksiyonu genellikle uzaklığın, maliyetin vb. en küçüklenmesi iken önceden belirlenmiş $p$ adet tesisin açılması söz konusudur. Doğrusal modele sahip $p$-medyan problemi ilk olarak 1964 yılında Hakimi tarafindan tanımlanmış ve literatürde kendisine yer bulmuştur (Church, 2008). Aşağıda doğrusal programlama modeline sahip $p$-medyan problemi yer almaktadır. Burada $k(\forall k \in K)$ potansiyel tesisleri ifade ederken $i(\forall i \in I)$ ise müşterileri ifade etmektedir.

Parametreler:

$w_{i}=i$ müşterisinin talebi

$d_{i k}=i$ müşterisinim $k$ tesisine olan uzaklığ $l$

$c_{i k}=i$ müşterisinim $k$ tesisine taşıma maliyet $i$

Karar değişkenleri:

$y_{k}=\left\{\begin{array}{ll}1 & k \text { potansiyel bölgeye tesis kurulursa } \\ 0 & \text { diğer durumda }\end{array}\right\}$

$x_{i k}=\left\{\begin{array}{cc}1 & \text { i müşterisi } k \text { tesisine atanırsa } \\ 0 & \text { diğer durumda }\end{array}\right\}$

Doğrusal programlama modeline sahip $p$-medyan problemi Denklem (1), (2), (3), (4), (5) ve (6)'da verilmiştir.

$$
\operatorname{Min} Z=\sum_{i \in I} \sum_{k \in K} w_{i} d_{i k} c_{i k} x_{i k}
$$

s.t.

$\sum_{k \in K} x_{i k}=1, \quad \forall i \in I$

$$
x_{i k} \leq y_{k}, \quad \forall i \in I, \forall k \in K
$$

$\sum_{k \in K} y_{k}=P$ 
$x_{i k} \in\{0,1\}, \quad \forall i \in I, \forall k \in K$

$y_{k} \in\{0,1\}, \quad \forall k \in K$

Burada amaç fonksiyonu, müşteriler ile tesisler arasındaki uzaklık ve taşıma maliyetlerini minimize etmeyi amaçlamaktadır. 2 numaralı kısıtta her bir müşterinin bir tesise atanması sağlanmıştır. 3 numaralı kısıt, ancak ve ancak bir tesis açılmış ise müşteri ataması gerçekleştirileceğini aksi durumda müşterinin atanamayacağını ifade etmektedir. 4 numaralı kısıtta ise $\mathrm{KV}$ tarafindan hizmet verilmesi istenilen sayıda tesisin açılması sağlanmaktadır. Son olarak 5 ve 6 numaralı kısıtlar ise işaret kısıtlarıdır. Tesis yer seçimi problemleri içerisinde gerçek hayatta en sık karşılaşılan problemlerden biri olan $p$-medyan problemi literatürde de sıklıkla çalışan problemlerden biri olmuştur. Narula, Ogbu ve Sam (Narula, Ogbu, \& Sam, 1977) tarafindan gerçekleştirilen çalışmada dal-sınır algoritması ile $p$-medyan problemi çözüme kavuşturulmuştur. Serra ve Marianov (Serra \& Marianov, 1998) tarafından gerçekleştirilen çalışmada ise belirsizlik altında $p$-medyan problemi ele alınmıştır. Talep, seyahat süresi veya mesafelerdeki belirsizlikler altında yeni tesislerin tespit edilmesi için oluşturulan model ile senaryolar kurulmuş ve mümkün olan en iyi performansa sahip konumun seçilmesi istenmiştir. An, Zeng, Zhang ve Zhao (An, Zeng, Zhang, \& Zhao, 2014) ise gerçekleştirdikleri çalışmada talep değişikliklerini dikkate aldıkları iki aşamalı bir model önermişlerdir.

NP-zor sınıfına giren $p$-medyan problemi küçük boyutlu problemler için kesin yöntemlerle çözülebilmekte fakat problemin boyutu artıkça optimal çözüm elde edilememektedir. Bundan dolayı sezgisel ve meta-sezgisel yöntemler ile çözümler elde edilmeye çalışılmıştır (Mladenovic, Brimberg, Hansen, \& Moreno-Perez, 2007). Alp ve Erkut (Alp \& Erkut, 2003) tarafından gerçekleştirilen çalışmada tesis yer seçimi problemi Genetik Algoritma (GA) kullanılarak çözüme kavuşturulmuştur. Rolland, Schilling ve Current (Rolland, Schilling, \& Current, 1996) ise $p$-medyan problemi için Tabu Arama (TA) sezgiselinden yararlanmışlardır. Domínguez ve Muñoz (Domínguez \& Muñoz, 2008) ise $p$-medyan problemini çözüme kavuşturmak için Yapay Sinir Ağlarını (YSA) kullanmışlardır. Resende ve Werneck (Resende \& Werneck, 2004) tarafından gerçekleştirilen çalışmada ise hibrit bir sezgisel geliştirilerek problem çözüme kavuşturulmuştur. Özçakar ve Bastı (Özçakar \& Bastı, 2012) ise sürü zekâsı tabanlı bir metasezgisel olan Parçacık Sürü Optimizasyonu (PSO) algoritması kullanılmıştır.

Durak ve Yıldız (2015) tarafından gerçekleştirilen çalışmada alternatif tesislerin seçimi için iki farklı model ele alınmıştır. Firmanın mevcut tesisinin de göz önüne alındığı birinci

$$
\operatorname{Min} z=\sum_{i \in I} \sum_{k \in K} w_{i}\left[\left(x_{i}-x t_{k}\right)^{2}+\left(y_{i}-y t_{k}\right)^{2}\right] * x_{i k}+\sum_{k \in K} f_{k} y_{k}
$$$$
\forall i \in I
$$$$
\sum_{k \in K} x_{i k}=1
$$$$
\sum_{i \in I} w_{i} x_{i k} \leq Q_{k} y_{k}, \quad \forall k \in K
$$

modelde maliyet eğrisi oluşturularak optimum tesis sayısı bulunmuştur. Mevcut tesisinin dikkate alınmadığı ikinci modelde ise farklı tesis sayılarının denenmesi sonucu oluşan maliyetler karşılaştırılmıştır. Hazırcı ve Şahin (2019) tarafından gerçekleştirilen çalışmada geçici iskân alanlarının seçimi için öncelikle Analitik Hiyerarşi Prosesi (AHP) ile alternatif alanlar belirlenmiş ve bu alanlara ilgili mahalleler $p$-medyan modeli ile atanmıştır. Erşen ve Sel (2020) tarafından gerçekleştirilen çalışmada ise alternatif tesislerin müşterilere atanmasında maliyetin yanı sıra karbon salınım miktarı da göz önüne alınmış ve böylelikle daha çevreci tesis yeri önerilerinde bulunulmuştur.

\subsection{Doğrusal Olmayan Programlamaya Sahip $P$ - Medyan Problemi}

Hakimi tarafından tanımlanmış olan temel p-medyan problemi ve ilgili probleme ait matematiksel model Bölüm 2'de anlatılmıştı. $\mathrm{Bu}$ bölümde ise çalışma kapsamında geliştirilen doğrusal olmayan programlamaya sahip p-medyan problemine yer verilmiştir.

Doğrusal olmayan programlamaya sahip p-medyan probleminde, alternatif tesislerin konumları bilinmemekte bir diğer ifade ile alternatif tesisler $\mathrm{KV}$ tarafindan belirlenmemektedir. $\mathrm{Bu}$ çalışmada geliștirilen matematiksel model ile alternatif tesislerin konumları belirlenmekte ve KV'ye sunulmaktadır. Model ile elde edilen tesisler ile müşteriler arasındaki uzaklığın minimize edilmesi için karesel Öklid uzaklığı tercih edilmiştir. Ayrıca müşteriler alternatif tesislere talepleri doğrultusunda atanmaktadır. Müşterilerin talepleri kadar tesislerin kapasitesi de tesis yeri seçim probleminde önemli bir husustur (Reese, 2006). Tesis yeri seçim probleminde önemli olan bir diğer husus ise tesislerin yatırım maliyetidir (Dantrakul, Likasiri, \& Pongvuthithum, 2014). Bundan dolayı çalışmada tesis kapasitesini ve yatırım maliyetlerini de içeren bir amaç fonksiyonu oluşturulmuştur. Aşağıda çalışma kapsamında geliştirilmiş olan doğrusal olmayan p-medyan problemine ve matematiksel modele eklenen parametre ve karar değişkenlerine yer verilmiştir.

Parametreler:

$Q_{k}=k$ tesisinin kapasitesi

$f_{k}=k$ tesisinin yatırım maliyet $i$

$x_{i}=i$ müşterisinin $x$ koordinatı

$y_{i}=i$ müşterisinin y koordinatı

Karar Değişkenleri:

$x t_{k}=k$ tesisinin $x$ koordinat

$y t_{k}=k$ tesisinin y koordinatı 
$\sum_{k \in K} y_{k} \leq P$

$x_{i k} \in\{0,1\}, \quad \forall i \in I, \forall k \in K$

$y_{k} \in\{0,1\}, \quad \forall k \in K$

$x t_{k}, y t_{k} \geq 0, \quad \forall k \in K$

Burada amaç fonksiyonu, müşteriler ile tesisler arasındaki uzaklık ve taşıma maliyetlerini minimize etmektedir. Alternatif tesisler ve müşteriler arasındaki mesafeyi minimize etmek adına karesel Öklid uzaklığından yararlanılmıştır. Ayrıca amaç fonksiyonuna kurulacak olan tesislerin yatırımları için gerekli olan yatırım maliyeti eklenmiştir. 8 numaralı kısıtta her bir müşterinin bir tesise atanması sağlanmıştır. 9 numaralı kısıt ile her bir tesisin belirli bir kapasiteye sahip olduğu ve tesise atanan müşteri taleplerinin en fazla tesisin kapasitesi kadar olabileceği ifade edilmektedir. 10 numaralı kısıt ile müşterilerin atanması sonucunda hizmet verebilen maksimum tesis sayısının, KV'ye alternatif olarak sunulmak istenilen tesis sayısı kadar olabileceği vurgulanmıştır. Son olarak 11, 12 ve 13 numaralı kısıtlar ise işaret kısitlarıdır.

Çalışmada doğrusal olmayan programlamaya sahip pmedyan problemini çözmek için GAMS 22.5 paket programından yararlanılmıştır. Ele alınan problem karmaşık tam sayılı doğrusal olmayan programlama- MINLP (Mix Integer Non-linear Programing) matematiksel modeline sahiptir. MINLP matematiksel modeline sahip olan problemleri optimal çözüme kavuşturmak için geliştirilmiş olan BARON (Branch-AndReduce Optimization Navigator) çözücü ile problem çözümü elde edilmiştir.

Çalışma kapsamında literatürden alınmış olan örnek veri seti Tablo 1'de yer almaktadır. 10 müşteriden oluşan veri setinde, müşterilere ait x-y koordinatları ve talepleri bulunmaktadır.

Tablo 1.10 müşteriye ait $x-y$ koordinatlarl ve talepler

\begin{tabular}{|c|c|c|c|}
\hline Müşteri & X Koordinatı & Y Koordinatı & Talep \\
\hline M1 & 28 & 48 & 4 \\
\hline M2 & 37 & 2 & 8 \\
\hline M3 & 25 & 30 & 2 \\
\hline M4 & 21 & 62 & 6 \\
\hline M5 & 49 & 16 & 1 \\
\hline M6 & 90 & 51 & 3 \\
\hline M7 & 60 & 83 & 7 \\
\hline M8 & 97 & 94 & 1 \\
\hline M9 & 61 & 29 & 2 \\
\hline M10 & 97 & 96 & 6 \\
\hline
\end{tabular}

Ele alınan örnek problemde alternatif tesis sayısı 4 olarak belirlenmiş ve bu alternatif tesisler içerisinden 3 tesisin hizmet sunması istenmiştir. Tesislerin ilgili müşterilere hizmet verebilmesi için gerekli olan yatırım maliyetleri sırası ile 250, 550,100 ve 400 olarak belirlenmiştir. Ayrıca kurulması planlanan tesislerin mevcut kapasiteleri 25, 20, 20 ve 15'tir. MINLP e-ISSN: 2148-2683 matematiksel modeline sahip p-medyan problemi ile elde edilen sonuçlar Tablo 2'de yer almaktadır.

Tablo 2. Tesis koordinatlarl ve tesislere atanan müşteriler

\begin{tabular}{|c|c|c|c|}
\hline $\begin{array}{c}\text { Açılan } \\
\text { Tesis }\end{array}$ & X Koordinatı & Y Koordinatı & $\begin{array}{c}\text { Atanan } \\
\text { Müşteri }\end{array}$ \\
\hline 1 & 77,706 & 82,588 & $6,7,8,10$ \\
\hline 3 & 24,000 & 52,000 & $1,3,4$ \\
\hline 4 & 42,455 & 8,182 & $2,5,9$ \\
\hline
\end{tabular}

Söz konusu örnekte alternatif 4 tesis içerisinden 1,3 ve 4 numaralı tesisler hizmete açılmıştır. 1 numaralı tesise $6,7,8,10$ numaralı müşteriler, 3 numaralı tesise 1,3,4 numaralı müşteriler atanır iken son olarak 4 numaralı tesise 2, 5, 9 numaralı müşteriler atanmıştır. Tesisler ve müşteriler arasındaki karesel Öklid uzaklığını ve tesis maliyetlerini göz önüne alan matematiksel modelin amaç fonksiyonu değeri ise 12694,011 olarak bulunmuştur.

\section{Sonuç ve Öneriler}

Tesis yer seçimi problemi gerek ciddi bir yatırım gerektirmesi açısından, gerekse lojistik maliyetlerini doğrudan ve dolaylı yollardan etkileyen ve uzun vadede olumlu ya da olumsuz etkilerini gösteren önemli bir karar problemidir. Firmalar arasındaki rekabetin artması sebebiyle müşteri odaklılığının önem kazandığ1 günümüz koşullarında, azalan hammadde kaynaklarına ve talep noktalarına yakınlık firmaların göz önünde bulundurması gereken en önemli faktörler arasında yer almaktadır. Bu çalışmada ise tesis yer seçimi problemlerinden biri olan ve gerçek hayatta da sıklıkla karşılaşılan $p$-medyan problemi ele alınmıştır. Doğrusal programlama modeline sahip $p$-medyan probleminde, müşterilerin atanacağı tesislerin bilgileri $\mathrm{KV}$ tarafından belirlenmektedir. $\mathrm{Bu}$ çalışmada ise alternatif tesislerin koordinatlarının matematiksel model yardımı ile KV'ye sunulması hedeflenmiştir. Bunun için MINLP matematiksel modeli geliştirilerek klasik tesis yer seçim problemlerinde alternatif tesis yerlerinin $\mathrm{KV}$ tarafından belirlenmesinin dışına çıkılarak, KV'ye alternatif tesisler sunulmak istenmiştir.

Ele alınan bu problem GAMS 22.5 paket programı BARON çözücüsü ile çözüme ulaştırılmıştır.

Çalışmamızda müşteri taleplerinin bilindiği varsayılarak model oluşturulmuştur. Gelecek çalışmalarda taleplerin belirsiz olduğu durum ele alınabilir. Ayrıca müşteriler ile tesisler arasındaki uzaklığın minimize edilmesi için karesel Öklid 
uzaklığı dikkate alınmıştır. Gelecek çalışmalarda doğrusal, Manhattan veya Öklid uzaklıklarından da yararlanılabilir.

\section{Kaynakça}

Alp, O., \& Erkut, E. (2003). An efficient genetic algorithm for the p-median problem. Annals of Operations Research, 122, 2142.

An, Y., Zeng, B., Zhang, Y., \& Zhao, L. (2014). Reliable p-median facility location problem: two-stage robust models and algorithms. Transportation Research Part B, 64, 54-72.

Bast1, M. (2012). The P-median Facility Location Problem and Solution Approaches. Online Academic Journal of Information Technology, 3(3), 46-75.

Church, R. L. (2008). BEAMR: An exact and approximate model for the p-median problem. Computers \& Operations Research, 35, $417-426$.

Dantrakul, S., Likasiri, C., \& Pongvuthithum, R. (2014). Applied p-median and p-center algorithms for facility location problems. Expert Systems with Applications, 41(8), 35963604.

Domínguez, E., \& Muñoz, J. (2008). A neural model for the pmedian problem. Computers \& Operations Research, 35, 404 $-416$.

Durak, İ., \& Yıldız, M. S. (2015). P- Medyan Tesis Yeri Seçim Problemi: Bir Uygulama. Uluslararast Alanya İşletme Fakültesi Dergisi, 7(2), 43-64.

Erşen, M. A., \& Sel, Ç. (2020). Türkiye'de Otomotiv Yan Sanayinde Çevreci Tesis Yeri Seçimi Problemi. Uluslararası Mühendislik Araştırma ve Geliştirme Dergisi, 12(1), 202209.

Hazırcı, M., \& Şahin, Y. (2019). Geçici iskân alanlarının seçimi için ahp temelli p-medyan modeli: Burdur örneği. Mühendislik Bilimleri ve Tasarım Dergisi, 7(2), 403 - 417.

Hillsman, E. L. (1984). The p-median structure as a unified linear model for location-allocation analysis. Environment and Planning A: Economy and Space, 16, 305-318.

Karaoğlan, İ. $\quad(2019,05$ 21). Kişisel Web Sitesi. http://www.ismailkaraoglan.com/1203604.html (2021,09 09)

Mladenovic, N., Brimberg, J., Hansen, P., \& Moreno-Perez, J. A. (2007). The p-median problem: A survey of metaheuristic approaches. European Journal of Operational Research, 179, 927-939.

Narula, S. C., Ogbu, U. I., \& Sam, H. M. (1977). Narula, S. C., Ogbu, UTechnical Note-An algorithm for the p-Median Problem. Operations Research, 25(4), 541-724.

Özçakar, N., \& Bastı, M. (2012). P-Medyan kuruluş yeri seçim probleminin çözümünde parçacık sürü optimizasyonu algoritması yaklaşımı. İstanbul Üniversitesi İ̧sletme Fakültesi Dergisi, 41(2), 241-257.

Reese, J. (2006). Solution methods for the p-median problem: An annotated bibliography. Networks, 48(3), 125-142.

Resende, M. G., \& Werneck, R. F. (2004). A Hybrid Heuristic for the p-Median Problem. Journal of Heuristics, 10, 59-88.

Rolland, E., Schilling, D. A., \& Current, J. R. (1996). An efficient tabu search procedure for the p-Median Problem. European Journal of Operational Research, 96, 329-342.

Serra, D., \& Marianov, V. (1998). Thep-median problem in a changing network: thecase of Barcelona. Location Science, 6(4), 383-394. 